\title{
La mujer como objeto (modelo) y sujeto (fotógrafa) en la fotografía
}

\author{
Woman as object (model) and subject (photographer) in the \\ photography
}

\author{
AnA M. MuÑoz-MuÑOZ \\ Instituto Universitario de Investigación de Estudios de las Mujeres y de Género. \\ Departamento de Información y Comunicación. Universidad de Granada. \\ anamaria@ugr.es \\ María Barbaño GonzÁlez-Moreno \\ Departamento de Información y Comunicación. Universidad de Granada. \\ barbanho@correo.ugr.es
}

Recibido: 14 de noviembre de 2012

Aprobado: 15 de abril de 2013

\section{Resumen}

Este trabajo cuestiona la evolución del papel de las mujeres en el ámbito fotográfico contemporáneo. A partir del estudio de las primeras mujeres fotógrafas, se analiza la situación de las mujeres como objeto (modelo) y sujeto (fotógrafa); se reflexiona sobre los condicionamientos sociales y la influencia de las imágenes que transmiten los medios de comunicación en la construcción y proyección de la imagen femenina en la fotografía, analizando las fotógrafas pioneras y más relevantes en la historia contemporánea. Finalmente se valora la desigualdad de género en relación con la capacidad de control sobre la imagen proyectada de las mujeres y su identidad a través del cuerpo en el ámbito de la fotografía feminista.

Palabras clave: fotografía, fotógrafas, cuerpo, identidad, mujeres.

Muñoz-Muñoz, A.M., González-Moreno, M.B. (2013): La mujer como objeto (modelo) y sujeto (fotógrafa) en la fotografía. Arte, Individuo y Sociedad, 26 (1) 39-54

\begin{abstract}
The aim of this study is to show whether the role of women in the contemporary photography has evolved. We analyze the situation of women as objects (model) and subjects (photographer) starting from a study of the first women photographers. We examine the social conditions and the influence of the images transmitted by the media in the construction and projection of the image of women, analyzing the pioneering and most relevant photographers in contemporary history. Finally we evaluate the gender inequality in relation to the ability to control the projected image of women and their identity through their body in the field of feminist photography.
\end{abstract}

Key words: photography, photographers, body, identity, women.

Muñoz-Muñoz, A.M., González-Moreno, M.B. (2013): Woman as object (model) and subject (photographer) in the photography. Arte, Individuo y Sociedad, 26 (1) 39-54 
Sumario: 1. Introducción, 2. Fotografía y mujeres, 3. Mujeres, imagen y medios de comunicación, 4. La fotografía feminista, 5. Las fotógrafas feministas y sus obras más relevantes, 6. Conclusiones. Referencias.

\section{Introducción}

La fotografía nacida en la primera mitad del siglo XIX es, como el resto de áreas artísticas, un ámbito dominado por los hombres (Carro Fernández, 2010). El papel de la mujer en la fotografía fue por ello reducido durante mucho tiempo a modelo situado ante la cámara, objeto que fotografiar. Con el paso de los años, ya a finales del siglo XIX, la fotografía llegó a convertirse en una de las pocas actividades creativas permitidas al género femenino. A partir de entonces las mujeres trabajarán como fotógrafas en un campo artístico creado por hombres. Será desde los años sesenta, momento del auge definitivo de la reivindicación del movimiento feminista, cuando las mujeres se revelan a través de la fotografía para denunciar las injustas situaciones y roles que deben cumplir en una sociedad patriarcal, reivindicando, así mismo, el poder de construcción de su propia imagen, mediante el uso de sus propios cuerpos como espacios de creación y crítica.

La aparición de estudios sobre la situación de la mujer en el arte coincidirá con el movimiento feminista, con la obra del psicoanalista Robert Stoller en 1968, Sex and Gender: the development of masculinity and femininity (Stoller, 1968). A la práctica política y artística se unirá la reflexión teórico-ideológica, aumentando el número de publicaciones editadas por décadas. Es a partir de este momento cuando se hace visible y es reconocido por la historia del arte el papel de la mujer en el campo fotográfico como artista. A pesar de todo ello, las reivindicaciones feministas por parte de las fotógrafas continúan en nuestros días, decididas no sólo a la búsqueda de una igualdad práctica en el presente, sino a la recuperación de la figura de la mujer que a lo largo de la historia había sido invisibilizada.

\section{Fotografía y mujeres}

La fotografía tiene significados polisémicos como consecuencia de sus diferentes usos; podemos hablar de fotografía como género artístico, como documento científico o histórico, o como testimonio vital de la vida del individuo. En todos ellos la mujer ha actuado como musa del artista, que suele ser varón, plasmando la mirada patriarcal sobre la imagen.

Toda fotografía se remite a un momento distinto al de su contemplación. La relación íntima que establece la fotografía con el tiempo pasado ha sido (y sigue siendo) tanto un señuelo como un problema para la teoría y la práctica del arte feminista (Reckitt, \& Phelan, 2005, p. 31).

La fotografía es la inmortalización de la mirada de un artista ante un instante, un momento. Este momento es visionado por el espectador desde otra perspectiva espacio-temporal y desde otro contexto histórico. Cada mirada es única y muy 
personal, lo que da lugar a diferentes interpretaciones sobre una misma obra. La fotografía es testigo de la historia, documenta y retrata tanto la historia en mayúsculas como la de las vidas privadas de las personas.

Desde el nacimiento de la misma, y a pesar de la voluntad de muchas mujeres, éstas se vieron apartadas de la producción fotográfica por evidentes motivos políticos y socioculturales. Cuando consiguieron incorporarse a ella lo hicieron a la sombra de sus maridos o sus padres, de los que aprenderían el oficio. En estos casos solían aparecer como sus ayudantes. Por ello algunas obras realizadas por mujeres podrían haber sido firmadas por sus "tutores" varones. En esta misma línea las pocas mujeres que alcanzaron un nivel autónomo como fotógrafas han sido tradicionalmente relegadas en la historia de la fotografía, siendo redescubiertas con el paso del tiempo.

Las primeras fotógrafas reconocidas en la historia de la fotografía fueron Constance Talbot y Anna Atkins. Constance Talbot ayudó a su esposo Henry Fox Talbot en los experimentos fotográficos que condujeron a la creación del calotipo. Anna Atkins, bióloga y amiga de Constance, aprendió el proceso del calotipo y en 1842 comenzó a documentar especies de algas marinas de las Islas Británicas a través de cianotipos. El resultado fue la publicación entre 1843 y 1853 de una serie de fotografías de algas bajo el título Photographs of British Algae: Cyanotype Impressions, considerado el primer libro ilustrado fotográficamente (Denny, 2009). Curiosamente no se sabe cuál de las dos fue de hecho la primera fotógrafa, porque no se han encontrado pruebas que lo atestigüen, consecuencia de la poca importancia que la historia ha dado a la mujer en este campo artístico (Núñez \& Oliva, 2011).

Fue a finales del siglo XIX, con la invención de la cámara de fuelle por el parisino André Adolphe Eugène Disderi, cuando la fotografía comenzó a extenderse por el mundo gracias a un grupo de fotógrafos itinerantes que mostraban la técnica de ciudad en ciudad, Disderi era uno de estos, debido lo cual su mujer Geneviéve Elisabeth Francart (1817-1878) quedaba al frente de su antiguo negocio en Brest. En este momento es cuando verdaderamente las mujeres se incorporan profesionalmente a este arte. Desde entonces la fotografía se populariza entre una clase burguesa urbana, dando lugar a una cierta democratización de la imagen, abaratando costes debido a su proceso mecánico-industrial, frente al elitismo tradicional de las Bellas Artes. Surge así la fotografía como técnica amateur también entre las mujeres.

En 1861, la fotógrafa sueca Hilda Sjölin (1835-1915) realizó la primera fotografía estereográfica de la bahía de Malmö en 1864. En 1865, Shima Ryuu (1823-1900) se convirtió en la primera mujer fotógrafa en Japón. En estas primera décadas proliferan las fotógrafas: unas eran aficionadas, como Alice Austen (1866-1952), mientras que otras lo hacían por necesidad, como la estadounidense Julia Shannon, que compatibilizaba la fotografía con su oficio de matrona. También las hubo que se aficionaron por casualidad, como Julia Margaret Cameron (1815-1879), que recibió una cámara como regalo por su cuarenta y ocho cumpleaños, y que destacó por sus retratos, considerándose como una pionera del pictorialismo (Gernsheim, 1975).

A comienzos del siglo XX las mujeres se integran al mundo de la fotografía como artistas, destacando entre ellas Zaida Ben Yusuf (1869-1933), que expuso en el Salón del año 1896 de The Linked Ring Brotherhood (La Hermandad del Anillo Engarzado) en Inglaterra, y a Gertrude Käsebier (1852-1934) cofundadora en 1902 del grupo 
Photo-Secession, y que despuntó como retratista en sus series de indios nativos y de mujeres. Tuvo como discípulas a Imogen Cunninghan (1883-1976), Anne Brigman (1869-1950) y Laura Gilpin (1891-1979) (Michaels \& Käsebier, 1992).

En la década de 1920 Berlín era el foco de todas las vanguardias. De entre las fotógrafas alemanas podemos destacar a Hanna Höch (1889-1978), Valentina Kulagina (1902-1987), Lucia Moholy (1894-1989), Marianne Brandt (1893-1983), Gertrud Arndt (1903-2000) y Grete Stern (1904-1999).

Durante todo el periodo de entreguerras se concentraron en París numerosos artistas procedentes de diversos países y estilos artísticos que no encontraban su sitio en las corrientes artísticas oficiales de sus países de origen. Entre las fotógrafas están las norteamericanas Berenice Abbott (1898-1991), Lee Miller (1907-1977) y Florence Henri (1893-1982). La primera mujer que realiza una exposición en aquel París es la fotógrafa francesa Laure Albin-Guillot (1879-1962). Como fotógrafas surrealistas destacan las francesas Claude Cahun (1894-1954) y Dora Maar (1907-1997). Otras fotógrafas procedentes de Alemania que se instalarían en Paris son: Ilse Bing (18991998) y Germaine Krull (1897-1985); y desde Austria Dora Kallmus (1881-1963). Mención aparte merecen varias fotógrafas que desarrollaron su trabajo al margen de estas corrientes artísticas en su lugar de residencia, como Madame Yevonde (18931975) en el Reino Unido, Lola Álvarez Bravo (1907-1993) en México, la alemana Annemarie Heinrich (1912-2005) en Argentina, y Karimeh Abbud (1896-1955) en el Líbano.

Después de la II Guerra Mundial, un gran número de fotógrafas vanguardistas europeas emigraron hacia países americanos, como la alemana Ellen Auerbach (19062004). Antes ya lo habían hecho sus compatriotas Lotte Jacobi (1896-1990) e Ilse Bing (1899-1998). En México se refugiaron las fotorreporteras Tina Modotti (18961942) y Kati Horna (1912-2000), en Londres la austriaca Lucia Moholy (1894-1989), mientras que Germaine Krull (1897-1985) se exilió en Asia.

En la última mitad del siglo XX se incorporan numerosas fotógrafas profesionales, formadas en universidades y escuelas de fotografía, como las japonesas Miyako Ishiuchi (1947- ) y Michiko Kon (1955- ). La fotografía artística de los 60 y 70 rompió con los cánones establecidos con la española Ouka Leele (1957- ).

En España también existieron pioneras. La almeriense Amalia López Cabrera (1838-1899) fue la primera que se dedicó a la fotografía a nivel profesional. La barcelonesa Anaïs Napoleón (1827-1916) fue la primera mujer en hacer daguerrotipos en España, especializándose en la realización de tarjetas de visita. Unos años más tarde Carme Gotarde i Camps (Olot, 1892-1953) ejerció como retratista profesional; Joana Biarnés (Terrassa, 1935- ) fue la primera reportera gráfica de Cataluña (CuevasMorales, 2009). Si por aquel entonces ya era duro ser mujer y artista, aún lo era más cuando se trataba en un medio relativamente nuevo.

La objetividad de la fotografía es mayor que la de la pintura, ya que debe haber una realidad ante la cámara para capturarla, bien sea captada con veracidad o recreada por el fotógrafo. El pintor no necesita crear una realidad y posteriormente retratarla, le vale con imaginarla para plasmarla en el lienzo. Esta necesidad de realidad presente ante el objetivo es la esencia de la fuerte carga de verdad que transmite al espectador la imagen fotográfica. 
Tanto el erotismo como el rol de la mujer han estado siempre presentes en el arte, jugando ésta el papel de sumisa o de promiscua. El principal protagonismo de las mujeres a lo largo de la historia del arte fue la representación de su cuerpo, de su imagen. Apareciendo antes como modelos que como fotógrafas, sufriendo una falta de dominio sobre su propia imagen, consecuencia de una estructura social patriarcal propia de la época.

Hans Bellmer, fotógrafo polaco que a lo largo de su carrera trabajó con la fotografía erótica, plantea "en qué medida la imagen de la mujer deseada está condicionada por la imagen del hombre que la desea" (Muthesius \& Riemschneider, 1998, p. 21). Bellmer fue el primer artista que trató el tema de que la imagen de la mujer es la que el hombre quiere que sea. Este prototipo de mujer ficticia habría sido creado a partir de la proyección de los deseos masculinos, extendiéndose en el tiempo como modelo ideal.

\section{Mujeres, imagen y medios de comunicación}

La imagen del cuerpo femenino proyectada a lo largo de la historia ha sido, sin lugar a dudas, muy cambiante por motivos económicos y políticos (Pérez Parejo, 2006). Así, desde la Venus de Willendorf, interpretada como símbolo de la fertilidad, hasta llegar a las imágenes de los medios de comunicación actuales, en las que la figura femenina aparece una y otra vez cargada de connotaciones sexuales, el cuerpo femenino ha sido utilizado como icono atendiendo a diversos intereses (religiosos, comerciales,...).

En la historia del arte desde que aparece el sistema patriarcal podemos observar el escaso número de mujeres que aparecen como artistas, por lo que podemos afirmar que el poder sobre la creación de la identidad femenina lo ha tenido siempre el hombre, creando y manipulando esa imagen de acuerdo con el imaginario masculino del momento. Estos cánones de belleza marcados por un sistema patriarcal han sido reconocidos y asumidos por las mujeres a lo largo del tiempo. Las mujeres han sido así esclavas del imaginario masculino de cada época, tratando de acercarse a un ideal que marca el camino hacia una perfección y una supuesta virtud, belleza y/o felicidad irreal. A su vez, este supuesto modelo de mujer perfecta, creado bajo la supervisión del hombre, terminaría por marcar la identidad femenina y por determinar cuando sus actos y actitudes son adecuados o no.

Una de las primeras mujeres ejemplo de la lucha por la igualdad de género en un contexto artístico es Valie Export, australiana nacida en 1940, la cual trabaja en diferentes medios como la performance, la fotografía, el vídeo y la escultura, al mismo tiempo que desarrolla una labor teórica en escritos sobre arte contemporáneo. Es una de las artistas más relevantes en el movimiento artístico feminista de finales de los años 60 y principios de los 70 .

En 1969, realiza una de las performances de más impacto en el mundo artístico del momento, Genital Panic (Bataille, Biesenbach \& Sontag, 2007). La artista, vestida de negro con un pantalón vaquero que descubre sus genitales y una metralleta colgada al cuerpo, se pasea por un cine de Múnich ofreciéndole sus genitales al público y apuntando con la metralleta a la cabeza de los espectadores de la fila anterior. Valie interpretó la conciencia que tiene la mujer de sus genitales y los mostró tal y como son. Las mujeres conocen su cuerpo y quieren que la sociedad sea consciente de esto, 
quieren recuperar el poder que les pertenece sobre sus propios cuerpos. Denuncia al mismo tiempo que las decisiones sexuales femeninas deben ser de las propias mujeres.

El prototipo de belleza marcado por el sistema es tan fuerte y está tan extendido, sin duda, gracias al poder de la imagen en la sociedad global actual. Los medios de comunicación se encargan de recrear en ella una realidad virtual, simulada, que atiende a las posibilidades del consumo. Todo es imagen, y toda imagen es susceptible de ser difundida, comercializada y puesta en venta al ciudadano, convertido en poco más que consumidor.

Los medios de comunicación han provocado un cambio en nuestra búsqueda de identidad. Así, nuestro cuerpo se expone ante un espejo que nos permite ver quiénes y cómo somos a través de nuestro reflejo en las imágenes. La democratización en la utilización del vídeo, la fotografía, la telefonía móvil avanzada e internet (sobre todo en el ámbito específico de chats, comunidades y redes sociales) permite a todos los ciudadanos generar y difundir imágenes, desarrollando de un modo esquizofrénico una serie de roles cambiantes sobre su propia persona. Ofrecemos sólo lo que queremos que los demás vean, creándonos la ilusión de supuestas personalidades ficticias que nos "mejoren" y atiendan a aquello que quisimos ser. Curiosamente esta aparente libertad de elección no esconde sino otro tipo de condena, la que nos somete al choque continuo realidad-ficción-deseo en el que cada vez se hace más complicado aceptarnos tal y como somos. Esta deriva nos conduce, una vez más, a un nuevo tipo de esclavitud de la imagen y la perfección (Kruger, 1998).

La consecuencia principal de todo esto es la falta de identidad que sufren las personas a través del consumismo, somos lo que compramos, como manifiesta Barbara Kruger en una de sus obras, I shop therefore I am (1987). Esta artista y escritora nacida en 1945, en Nueva Jersey, basa principalmente su obra en la reflexión y crítica de los medios de comunicación. En su trayectoria profesional como escritora reflexiona sobre todos los medios de comunicación, especialmente la televisión, aunque en su trayectoria artística la publicidad sea su principal objetivo.

Su trabajo se basa en criticar y hacer contrapublicidad a través de fotomontajes e instalaciones, imágenes en blanco y negro con eslóganes en blanco y rojo. Las imágenes que aparecen en sus obras son una combinación de fotografías propias junto a otras sacadas de anuncios publicitarios realizados por otros fotógrafos.

Los eslóganes buscan el choque y la reflexión del espectador. Kruger trata de forzar la crítica como modo de llegar al público para hacerlo pensar, para que medite sobre qué es la publicidad, el capitalismo y el lugar en que se sitúan como consumidores. Además, hace especial hincapié en el papel de la mujer al respecto, utilizando su imagen como objeto y convirtiéndola en sumisa de los cánones establecidos por otros.

Otra artista contemporánea que basa su obra en la contrapublicidad es Jenny Holzer (Ohio, 1950- ), que emplea la proyección de eslóganes interrogantes sin respuesta en busca de la reflexión del espectador. Proyecta sus eslóganes en edificios, puentes, carreteras, letreros luminosos... cualquier elemento perteneciente al espacio urbano, invadiendo el ámbito público, de forma que los espectadores son todos los ciudadanos de la ciudad donde se encuentre su obra. Como ejemplo de sus proyecciones en la Times Square de Nueva York destaca Protect me from what I want (1983-1985). 


\section{La fotografía feminista}

En Estados Unidos, tras conseguir en los años 20 el sufragio universal, el movimiento feminista pierde impulso debido a su débil capacidad organizativa y falta de cohesión. Será ya en los años 60 cuando resurja con más fuerza y entereza, con unos objetivos unificados y una estructura sólida. En el momento que retoma su lucha por los derechos de las mujeres el arte es utilizado como herramienta política. Las artistas que trabajaban en los círculos feministas a partir de los años 70 dieron a su obra una fuerte orientación crítica, tanto política como social, primero en el contexto norteamericano y más tarde en el europeo.

Las mujeres comienzan a ser conocidas y reconocidas en diferentes campos artísticos, cambiando el estereotipo de su imagen en el arte y reivindicando un reconocimiento real como artistas. Las herramientas más utilizadas en esta época para hacer crítica social fueron la performance o el arte de acción, nuevos modos de creación artísticos que son inmortalizados y documentados gracias en gran parte a la fotografía (Caballero, 2008).

En estos tiempos de cambio surge la Nueva Izquierda, formada por movimientos antirracistas, estudiantiles, pacifistas y feministas. Estos cuatro movimientos luchaban unidos con el objetivo de la consecución de la igualdad y la libertad de las minorías oprimidas. Durante la aparición de la Nueva Izquierda, las feministas perciben que dentro de la organización se siguen encargando de las "tareas de mujeres": preparar el café, atender a los hombres, etc. Así, la voz de los hombres no sólo seguía marcando la política oficial, sino que paradójicamente también dominaba dentro de los grupos contraculturales. En este contexto, en 1967, con la creación del New York Radical Women (NYRW), surge lo que podríamos denominar el verdadero movimiento feminista, más radical, que influyó en todos los sectores tanto políticos y sociales como culturales y artísticos, incluido el de la fotografía.

Esta organización tuvo un corto período de vida, pues en 1970 se disuelve, pero los pilares de este movimiento habían calado hondo en destacados sectores de la sociedad americana, hasta el punto de que durante esta etapa se logra impartir clases de arte feminista en colegios de California (Carro, 2010).

El arte feminista, se basaba en 3 grandes pilares: en primer lugar, la obra de arte como instrumento para la reflexión sobre la experiencia de género, en segundo lugar la investigación con nuevos materiales y formas de expresión para así acabar con los usos jerárquicos de los mismos; finalmente, la exploración de la imaginería vaginal para representar la sexualidad femenina de una manera nueva y más positiva, a la par que se despertaba la conciencia de las alumnas sobre su cuerpo e identidad sexual (Carro, 2010, p. 95).

Las mujeres ponen de manifiesto su inconformismo respecto al lugar que le otorga el sistema patriarcal y se posicionan políticamente para denunciar esta situación. Se sublevan para acabar con la sumisión al poder, al hombre, acabando con el estereotipo de "putas y sumisas" (Amara, Zappi \& Martínez, 2004), de esclavas de la casa, de objetos sexuales. La mujer reivindica su valía como ser en todos los ámbitos políticos, 
socioculturales y artísticos. Dentro de este ambiente de reivindicaciones ideológicas el arte se convierte en un elemento fundamental de provocación social y difusión de ideas contra el sistema patriarcal.

El feminismo trabaja con la base de la propia experiencia vital de las mujeres para denunciar los roles que les ha otorgado el sistema. La fotografía aparece de este modo como el medio principal de denuncia ante estas situaciones, bien reales o bien escenificadas (de una forma más o menos metafórica) en performances o acciones artísticas (Diego, 2011). Los nuevos grupos artísticos tratarán de traspasar los obstáculos existentes entre la experiencia artística y la vital, unir ambas de modo radical para alejarse del elitismo y acercarse lo más posible a la realidad social. La fotografía aquí permite fijar en la memoria acciones efímeras, que perdurarán en el tiempo y se difundirán gracias a ella. El arte y la fotografía se desvinculan en este punto de la necesidad de belleza, teniendo como principal objetivo llamar la atención sobre problemas político-sociales de otro modo silenciados.

Sólo así podemos entender la importancia del papel de la mujer en los nuevos grupos surgidos y la decidida utilización política del arte, que aparece estrechamente ligado a grupos políticos y culturales que también reivindican su lugar en la sociedad, derechos que el sistema les ha negado. Es por ello el nacimiento simultáneo de movimientos sociales, ya que a pesar de reclamar al sistema diferentes derechos, a todos les debía justicia el capitalismo y el patriarcado. Así pues las mujeres utilizan el arte como herramienta socio-política de denuncia social. En el contexto fotográfico usan su cuerpo como herramienta de manifestación en la lucha de recuperación del poder de sus propios cuerpos, de sus propias imágenes. El sometimiento social que sufren las mujeres artistas acaba en la ruptura de estos valores patriarcales y en la visibilidad de las artistas reconocidas como un ser crítico, inteligente y consciente del mundo que le rodea, de sus capacidades a todos los niveles.

Será ya desde los años 70 cuando surja una fotografía dirigida a realizar una crítica político-social desde una perspectiva feminista, trazando una línea que continúa hasta nuestros días. Fueron y son numerosas las mujeres que eligieron la cámara como arma de provocación y crítica social, cabe destacar que siempre nos referimos al sistema patriarcal occidental, a las mujeres americanas y europeas, de clase media-alta y de raza blanca en la mayoría de los casos, con estudios universitarios y de pensamiento e ideología liberal. Los temas abordados fueron el alma crítica de las obras de este movimiento: el cuerpo, la mujer, el sexo, el género, la raza negra y la homosexualidad, temas tabúes en una sociedad de consumo que aliena, homogeneiza y manipula. De esta manera las personas que se salieran de los cánones de la normalidad serían expulsadas como grupos de minorías subculturales.

\section{Las fotógrafas feministas y sus obras más relevantes}

La fotografía feminista se centra en la autorrepresentación de las mujeres en el mundo, la situación social que ocupan y los roles que la sociedad patriarcal ha determinado para ellas. Estas representaciones son al mismo tiempo una crítica al cometido de las mujeres a lo largo de la historia, situando la época de finales de los años 70 y principio de los 60 como el momento del nacimiento de esta corriente artística. 
Son muchas las mujeres que van a participar en la crítica socio-política a través de la fotografía, empleando la mayoría de las veces el autorretrato como base para la crítica de los principales campos sociales en los que las mujeres están sometidas. Como ejemplo de fotógrafas feministas mencionaremos aquellas que se declaran públicamente como "artistas feministas" y cuya obra se expone en el Elizabeth A. Sackler Center for Feminist Art del Museo de Brooklyn: Boryana D. Rossa (1965), artista multidisciplinar que trabaja a lo largo de su carrera con vídeo, fotografía, performance y cine, entrelazando el bioarte, la biotecnología y el feminismo; Katy Grannan (1969- ), fotógrafa americana cuya obra se centra en la fotografía documental desde una perspectiva de género; Neeta Madahar (1966- ), artista interdisciplinar que trabaja con la fotografía y los medios de comunicación, siendo lo más representativo de su obra fotográfica la relación que plantea entre las mujeres y las flores. Cass Bird's, artista dedicada a la fotografía, cuyos temas principales son el lesbianismo, el amor, la vida y la mujer; plasmando en sus imágenes escenas documentales de vidas que se resisten a seguir los patrones sociales y que al mismo crean alternativas; Zineb Sedira (1963- ), artista multidisciplinar cuyos temas principales son la representación y los feminismos globales; Laurie Simmons (1949- ), fotógrafa de maquetas, creadora de imágenes narrativas y psicológicas, siempre desde una perspectiva feminista; Tomoko Sawada (1977- ), fotógrafa japonesa que explora la imagen y la representación desde su obra, centrándose en la pérdida de identidad entre las semejanzas del individuo; Lili Almog (1961- ), fotógrafa israelí que comienza su trayectoria profesional como reportera gráfica, si bien posteriormente centra su carrera en la fotografía feminista siendo el cuerpo femenino y la psicología el centro de su obra; Nanon Floyd (1956- ), artista especializada en la fotografía documental feminista, trabajando con la representación y la experiencia de los cuerpos de mujeres; Joanne Leonard (1924-2011), escritora y fotógrafa preocupada por cualquier desigualdad social, utilizaba sus imágenes como medio de crítica y denuncia a las injusticias sociales; Ángela Jiménez (1975- ), cuyo trabajo fotográfico se bifurca en fotoperiodismo y fotografía freelance, aunque la perspectiva de género está presente en toda su obra; Meghan Boody (1964- ), fotógrafa y escultora multimedia que trabaja únicamente con niñas y mujeres jóvenes en situaciones aterradoras, trabas impuestas por la sociedad y la cultura; Dotty Attie (1938- ), artista que utiliza la cámara como herramienta reivindicativa de los estándares socioculturales que sufren las mujeres.

Sobre las fotógrafas que han representado su obra simultáneamente como objeto y sujeto destacan:

\section{Judy Chicago}

La primera mujer reconocida en la historia del arte como artista feminista es Judy Chicago, nacida en 1939, artista, escritora y educadora americana que decide romper con los patrones convencionales del binomio arte-mujeres. Sus obras han sido expuestas en América, Europa, Oceanía y Asia, recorriendo el mundo a lo largo de los más de cincuenta años de carrera profesional que la avalan. Nacida en Chicago de donde toma parte de su nombre artístico, en una familia de clase media-alta se convierte en la principal artista de género consiguiendo dar la vuelta al mundo a través de sus obras. 
Centramos nuestra atención en su fotografía Red Flag (1971) que fue la obra que más polémicas despertó como arte feminista. El sentido de la obra no fue captado por el público espectador que interpretó el tampón como un pene atribuyéndole el significado de castración. Sin embargo, lejos de esta interpretación errónea, la artista nos muestra una acción común entre las mujeres, de retirarse un tampón durante la menstruación y visibilizarlo, denunciando la ocultación que la cultura occidental ha tenido siempre ante la menstruación, un tema biológico al que a lo largo de la historia, en numerosas civilizaciones, se le han atribuido connotaciones negativas.

Judy Chicago, a sus setenta y cuatro años, continúa su actividad profesional realizando pinturas, instalaciones, arquitectura y fotografía como herramientas para mostrarle al mundo su perspectiva de éste y criticar desde una postura feminista las injusticias que las mujeres aún hoy sufren en occidente.

\section{Hannah Wilke}

Esta artista es una de las pioneras en el arte feminista, nacida en Nueva York en 1940 en el seno de una familia de clase media-alta. En 1962 obtuvo la licenciatura en Bellas artes y en Ciencias de la educación.

Comienza su carrera como escultora, pintora y grabadora, y a partir de los años 70 comienza a trabajar la fotografía y el vídeo como medios de documentación de las performances que ella protagonizaba. En muchas ocasiones usaba su propio cuerpo desnudo y su vagina como medio crítico y expresivo. Esto le supuso muchas críticas negativas por colectivos feministas, que la tachaban de "exhibicionista narcisista" por ser guapa y tener un cuerpo bonito. Pero a lo largo de su carrera Hanna Wilke, enferma de un cáncer terminal que acaba con su vida en 1993, se sigue fotografiando y continúa trabajando con la cámara y su cuerpo desnudo, entonces enfermo, con su serie Intra-Venus (Pultz, 2003), lejos de aquel cuerpo joven, delgado y bello con el que había estado trabajando hasta el momento. Su carrera estuvo marcada por numerosas becas y proyectos entre Europa y América, con profusión de reconocimientos como artista feminista. El rol de las mujeres en la casa, las mujeres como objeto sexual, las mujeres artistas, las emociones femeninas, el dolor, la enfermedad, la dignidad humana y la muerte fueron los temas que más abordó en sus obras todo ello con un toque muy natural mediante la proyección de imágenes de su propia vida. Fue la primera artista en incorporar la iconografía de la vagina a sus obras y en tener su propia galería de arte, lo que la ayudó a mantener una potente trayectoria artística en vida. Obviamente su figura sigue presente en el arte contemporáneo feminista como una de las maestras (Wilke, Fernández Orgaz, Goldman \& Vicente Aliaga, 2006).

Como ejemplo de su trabajo fotográfico destacamos So Help Me Hannah: What Does This Represent / What Do You Represent (Reinhart) (1978-1984), protagonizada por su cuerpo desnudo en el rincón de una habitación siendo su vagina el punto de fuga de la imagen dirigiendo la mirada del espectador hacia él. Rodeada de armas y juguetes y como única prenda que viste su cuerpo unos zapatos de tacón altos, Hannah Wilke intenta que el espectador reflexione sobre la situación de las mujeres del momento y podríamos decir que también de la actualidad a través del eslogan que inserta en la parte inferior de la imagen: What does this represent. What do you do represent. Denunciando la situación de las mujeres como objeto sexual, el rol y 
el poder que ésta ocupa en la sociedad americana. Las armas simbolizan la presión cultural a la que están sometidas las mujeres por el canon de belleza, condicionando éste la posición social de las mujeres. Esta obra es un ejemplo de la naturalidad con la que la artista trata al cuerpo femenino, la dureza de sus imágenes y la belleza de su cuerpo por la que fue injustamente criticada.

\section{Martha Rosler}

Nacida en Brooklyn, Nueva York en 1943, ciudad que la ha visto nacer, crecer y desarrollarse como artista, y donde actualmente vive y trabaja.

Martha Rosler crea sus obras a partir de la performance, la fotografía, el vídeo e instalaciones. Licenciada en Bellas artes y docente de diferentes universidades americanas y europeas, la artista vive de sus ingresos como docente y conferenciante en congresos. Al mismo tiempo es autora de numerosos libros de arte y de fotografía (Rosler, 2012).

La obra de esta artista está marcada por la representación de la vida pública y la privada, en la mayoría de los casos desde una perspectiva feminista. Las guerras, las casas y los medios de comunicación son otros de los temas que protagonizan sus obras. El arte de Martha Rosler muestra un fuerte compromiso social, fusionando lo público y lo privado para demostrar que la política no existe sólo en el ámbito público, sino que está incrustada duramente en el ámbito privado. Abre las puertas del ámbito privado, de las casas, de las cocinas, de las mujeres, de las desigualdades sociales en Estados Unidos para fotografiar performances que muestran a la "vida pública" el escenario en el que la sociedad estadounidense vive, la realidad que las mujeres americanas sufren a través de los roles socioculturales y políticos impuestos por el sistema.

En el campo de la fotografía Martha Rosler trabaja especialmente con fotomontajes. Una de sus series feministas más potentes de fotomontaje es Body Beauty, or Beauty Knows No Pain (1965-1974), en el cual hace una severa crítica al trato que la publicidad tiene sobre la mujer y su cuerpo. La mayoría de la colección fue publicada por revistas no comerciales feministas americanas que ofrecían arte como cultura, cultura fuera del circuito comercial. Su obra $S M L$, parte de esta serie, es un fotomontaje que con su título hace referencia al tallaje de ropa, tres modelos que anuncian ropa de lencería, con miradas seductoras, melenas al viento y cuerpos perfectos según el canon de belleza actual.

Otra de sus colecciones feministas es Bringing the War: House Beautiful (19671972) en la cual la crítica principal es cómo el consumismo nos abstrae de la realidad, cómo el rol de las amas de casa impide a las mujeres ser libres, atándolas y alienándolas, haciendo de ellas seres pasivos en un sentido físico y mental.

Ambas colecciones son muy significativas para el arte feminista contemporáneo ya que fueron obras no comerciales nacidas del feminismo radical de los años sesenta. Representan el papel que desempeñan las mujeres en la sociedad y al mismo tiempo, los grandes problemas del momento en el mundo como las guerras. Problemas muy diferentes, que los medios de comunicación manipulan de manera arbitraria, consiguiendo una alienación social de la conciencia moral que hace sentirse al espectador ajeno a los mismos, restándole el valor que verdaderamente tiene. La 
artista denuncia esto utilizando imágenes de los medios de comunicación en su obra, unificando lo público y lo privado en una única pieza.

En la actualidad Martha Rosler, a sus casi setenta años, continúa la lucha contra injusticias políticas y sociales a través de sus obras, mediante el vídeo, fotografía, instalaciones, escritos y performances. Sus obras siguen la misma línea con la que inició su carrera, pero ahora consolidada.

\section{Ana Mendieta}

Nacida en La Habana en 1948 y exiliada de manera involuntaria a los Estados Unidos en 1960, tuvo una vida difícil que marcó su obra. Es una artista mundialmente conocida, especialmente a partir de 1985, tras su muerte en extrañas circunstancias de la que se acusa a su marido.

Ana Mendieta es una de las primeras mujeres que hace crítica del feminismo del momento liderado, por mujeres de raza blanca. Como mujer y artista en un mundo patriarcal, y como cubana en un mundo de blancos, decide unir su obra a la lucha por el reconocimiento de otro tipo de mujeres con los mismos valores e ideales, pero sin discriminación por el color de piel hacia sus semejantes.

La fotografía y el vídeo es el medio de documentación de sus performances (Cabañas, 1999). Utilizando su propio cuerpo como medio de transmisión del mensaje, este se convierte en un escenario crítico, que utiliza también de un modo no visible a través de huellas y siluetas. Rompe la línea de lo verbal y corporal ofreciendo muchas lecturas de sus obras.

En su obra destaca la simbología de su serie Glass on body (1972) en la que aplasta su cuerpo contra un cristal consiguiendo una imagen distorsionada del mismo, denunciando la opresión que sufren las mujeres por la sociedad y la cultura del momento, dominadas por hombres que secundan a la mujer a una posición injusta y denigrante. La violencia física contra el cuerpo de las mujeres va más allá de una mera representación simbólica.

Toda su obra está marcada por la búsqueda de la identidad, quiénes somos y quiénes nos hacen creer que somos, jugando con la posición en la que nos encuadra la cultura y rompiendo esos límites establecidos entre formas y sexualidad.

Una de las series más llamativas de la artista es Facial Hair Transplant (1972), el proyecto final con el que culminó sus estudios en la Escuela de Arte de Iowa (Ruido, 2002). Una obra llena de simbología, en la que utiliza el pelo como herramienta para denunciar los estándares de género que ofrecía y ofrece la cultura occidental, al tiempo que pone en duda los límites de la identidad sexual, rompiendo las barreras del prototipo del género femenino a través de implantes de pelos en la cara, recreándose desde el bigote a la barba. La artista logró este efecto con ayuda de un compañero de clase que se ofreció a cortarse la barba para que posteriormente ella se la pegase en el rostro simulando atributos propios del género masculino.

Ana Mendieta siguió creando hasta días antes de su muerte, y es considerada una de las referentes mundiales en fotografía feminista, denunciando el valor que es dado por el patriarcado a la identidad femenina y a la posición artística de las mujeres. 


\section{Nan Goldin}

Fotógrafa documental nacida en 1953 en Washington D.C. Licenciada en Bellas artes por la Universidad de Boston, su obra se centra en la captura del momento a través de instantáneas con el principal objetivo de retener el tiempo a través de la cámara, de inmortalizar un instante.

Sus imágenes están llenas de realismo y naturalidad. Nan Goldin retrata a sus amistades y a ella misma, defiende que uno sólo puede expresar lo que ha vivido, por lo que la obra de la artista es una colección de imágenes de su vida privada, lo cual representa el rasgo diferencial de su fotografía: la artista forma parte real de los hechos que documenta (Qualls, 1995). En los años 80 las drogas toman el control de su vida, aunque Goldin continúa retratando su realidad desde una clínica, el autorretrato en esta etapa de su carrera es quien toma protagonismo, con imágenes cargadas de espontaneidad y duros momentos de su propia vida (O' Reilly, 2009).

Muchas de sus obras denuncian la violencia de género, autorretratando los malos tratos que ella misma sufrió. Como por ejemplo sus fotografías Nan one month after being betterd (1984) y Heart-shaped Bruise, en las que la artista aparece como protagonista, una fotografía documental testigo del maltrato que sufrió por parte de su ex-pareja. Un duro documento que refleja las fuertes consecuencias de una cultura patriarcal en la cual las mujeres salen duramente golpeadas física y psicológicamente.

Para la artista hacer fotografías era un hecho cotidiano más de su vida, como dormir, comer... logra así la espontaneidad de sus imágenes y la realidad de un momento que la artista nos transmite (Sayre, 1994).

\section{Cindy Sherman}

Fotógrafa, modelo y cineasta nacida en Nueva Jersey en 1954. Estudió Bellas artes en la Universidad de Buffalo, donde se interesó por la pintura, inclinándose al poco tiempo por la fotografía, que le daba más posibilidades para crear su obra.

Cindy Sherman es modelo de sus propias fotografías y de sus películas. Con el maquillaje y el vestuario consigue convertirse en un personaje que da vida a sus obras, criticando los cánones femeninos culturalmente establecidos y extendidos por los medios de comunicación. El canon de belleza y la presión que ejerce el sistema capitalista en la mujer a través de los medios de comunicación y la industria de la cosmética es el tema principal en sus autorretratos, que son sus obras más importantes y representativas.

Entre 1970 y 1980 la artista alcanza el reconocimiento por primera vez con una serie de fotografías titulada Film Stills, en la cual todas las imágenes son en blanco y negro. En ellas interpreta escenas de películas de serie B y de la nouvelle vague que fueron escritas pero que nunca llegaron a ser rodadas. Lo esencial de esta serie es la escenificación que la artista realiza, ella misma como actriz, el maquillaje, la propia escena (Qualls, 1995).

En la actualidad esta artista continúa trabajando, interpretando los personajes de sus obras y jugando con la contrapublicidad y la imagen de los medios.

\section{Esther Ferrer}

En el ámbito español también tenemos artistas que formaron y forman parte de este movimiento de fotógrafas feministas que nace a finales de los años 60 y principio 
de los 70. En este caso destacamos a Esther Ferrer, nacida en San Sebastián en 1939, periodista y artista precursora de la performance en España.

Comienza su trayectoria profesional como periodista en el año 1961 y como docente, dando clases en una escuela experimental de arte de Guipúzcoa. En 1967 se incorpora a uno de los grupos más vanguardistas españoles de arte de acción, ZAJ (Ferrer, 1995). Compagina su carrera artística con la periodística, publicando artículos culturales en diarios como El País.

Ha asistido a los principales festivales de performances, ha impartido talleres y conferencias en varias escuelas de artes y universidades de todo el mundo, y se le han otorgado numerosos premios, como el Premio Nacional de Artes Plásticas en 2008.

En su carrera artística trabaja especialmente la pintura, la performance y la fotografía, siendo protagonista ella misma de muchas de sus imágenes, utilizando el cuerpo como medio de expresión.

La obra de Esther Ferrer es considerada anarquista y en ocasiones al mismo tiempo feminista. A través de sus performances los temas más tratados son el tiempo y el espacio, la identidad y la situación dentro del mismo. Sus obras están cargadas de denuncias culturales. Como ejemplo de su obra fotográfica podemos destacar Eurorretrato (1997), la identidad a través de la cantidad económica que poseemos.

En la actualidad continúa trabajando sobre su cuerpo: una de sus últimas performance fue realizada el 26 de enero de 2012, en el museo Es Baluard (Palma de Mallorca.

\section{Conclusiones}

A pesar de las reivindicaciones manifestadas por las mujeres, aún queda un largo camino por recorrer. La alienación ejercida por los principales pilares del patriarcado (cultura, educación y medios de comunicación), sigue haciendo difícil recuperar el poder sobre la construcción de su propia imagen. Al mismo tiempo, el número de nuevas artistas feministas continúa creciendo, expandiendo sus denuncias y críticas desde y contra un sistema que continúa marginándolas.

Incluso hoy día la imagen de la mujer sigue dominada por unos patrones ligados al poder capitalista-patriarcal. Como resultado, el cuerpo de las mujeres se convierte en mero producto de reclamo comercial. Los cánones de belleza se han ido modificando en el tiempo, pero siempre conservando su intencionalidad.

Por otro lado, tras el análisis de las obras de las fotógrafas más relevantes de las últimas décadas, podemos afirmar la existencia de una corriente feminista que trabaja la fotografía esencialmente con el cuerpo femenino, tratando de subvertir los valores que le han sido tradicionalmente otorgados a la mujer en este área. Recuperar la capacidad de construcción de la imagen femenina por las propias mujeres es uno de los objetivos de estas artistas.

El reconocimiento de las artistas femeninas continúa siendo escaso. El número de mujeres artistas que exponen en museos y galerías es aún inferior al de artistas varones. De la misma manera la historia del arte aún hoy se encuentra lejos de alcanzar la igualdad de género. Afortunadamente este hecho está tratando de ser rectificado, si bien todavía existe un gran número de mujeres merecedoras de estar en el mismo lugar que sus compañeros varones. 


\section{Referencias}

Amara, F., Zappi, S., \& Martínez, S. M. (2004). Ni putas ni sumisas. Madrid: Cátedra. Bataille, G., Biesenbach, K., \& Sontag, S. (2007). Into me/ out of me: [ausstellung; P.S.1 contemporary art center, a MOMA affiliate, New York, 25. juni - 25. September 2006; KW institut for contemporary art, berlin, 25. november 20064. märz 2007; MACRO museo d'arte contemporanea di roma, 21. april - 30. september 2007]. Ostfildern: Hatje Cantz Verlag.

Caballero, A. (2008). La mujer, la mujer-artista, el arte (el objeto). Escáner Cultural: Revista virtual de arte contemporáneo y nuevas tendencias, 10(103) Recuperado el 2 de agosto de 2012, de http://revista.escaner.cl/node/706

Cabañas, K. M. (1999). Ana Mendieta: "Pain of Cuba, Body I Am". Woman's Art Journal, 20(1), 12-17.

Carro Fernández, S. (2010). Mujeres de ojos rojos. Del arte feminista al arte femenino. Gijón: Trea.

Cuevas-Morales, S. (2009). La mujer tras la cámara: Fotografía en femenino. Revista Maginaria, 3. Recuperado el 2 de agosto de 2012, de http://www.ciudaddemujeres. com/articulos/La-mujer-tras-la-camara-fotografia

Denny, M. (2009). Royals, royalties and remuneration: American and british women photographers in the Victorian era. Women's History Review, 18(5), 801-818. doi: $10.1080 / 09612020903282183$

Ferrer, E. (1995). The artist in the swarming stage of making. Paper presented at the Symposium de Hetapollohaus - Eindhoven -(Holanda) - 1995 - Sobre el papel del arte y el artista en nuestra sociedad post-moderna. Recuperado el 3 de agosto de 2012, de http://www.arteleku.net/estherferrer/EFerrer.html

Gernsheim, H. (1975). Julia Margaret Cameron: Her life and photographic work. Millerton, N.Y: Aperture.

Kruger, B. (1998). Mando a distancia: Poder, culturas y el mundo de las apariencias. Madrid: Tecnos.

Michaels, B. L., \& Käsebier, G. (1992). Gertrude Käsebier: The photographer and her photographs. New York: H.N. Abrams.

Muthesius, A., \& Riemschneider, B. (Eds.). (1998). El erotismo en el arte del siglo $X X$. Köln: Taschen.

Newman, C. (2001). Mujeres tras la cámara. Barcelona: RBA.

Núñez, I., y Oliva, L. (2011). Sinrazones del olvido: Escritoras y fotógrafas de los siglos XIX y XX. Barcelona: Icaria.

O' Reilly, S. (2009). The body in contemporary art. New York: Thames \& Hudson.

Pérez Parejo, R. (2006). El canon de belleza a través de la historia: Un método de descripción de personas para alumnos de E/LE. Espéculo. Revista de estudios literarios, 34. Recuperado el 10 de Julio de 2012, de http://www.ucm.es/info/ especulo/numero34/canonbe.html

Pultz, J. (2003). La fotografía y el cuerpo. Madrid: Akal.

Qualls, L. (1995). Performance/photography. Performing Arts Journal, 17(1), 26-34.

Reckitt, H., \& Phelan, P. (2005). Arte y feminismo. London: Phaidon.

Rosler, M. (2012). Martharosler. Recuperado el 5 de diciembre de 2012, de http:// www.martharosler.net/ 
Ruido, M. (2002). Ana Mendieta. Guipúzcoa: Nerea.

Sayre, H. M. (1994). Scars: Painting, photography, performance, pornography, and the disfigurement of art. Performing Arts Journal, 16(1), 64-74.

Wilke, H., Fernández Orgaz, L., Goldman, S., \& Vicente Aliaga, J. (2006). Hannah Wilke: Exchange values. Vitoria-Gasteiz: Artium, Centro-Museo Vasco de Arte Contemporáneo. 